\title{
Smile attractiveness perception regarding buccal corridor size among different facial types
}

\section{Percepcja atrakcyjności uśmiechu w zależności od wielkości korytarza policzkowego w różnych typach twarzy}

\author{
Vahid Mollabashi ${ }^{1, A-F}$, Masoud Abolvardi ${ }^{1}, A-F$, Marzieh Akhlaghian ${ }^{2, B, D, F}$, Mohammad Ibrahim Ghaffari ${ }^{3, C}$ \\ ${ }^{1}$ Department of Orthodontics, School of Dentistry, Hamadan University of Medical Sciences, Iran \\ ${ }^{2}$ Department of Prosthodontics, School of Dentistry, Shiraz University of Medical Sciences, Iran \\ ${ }^{3}$ Department of Biostatistics, School of Public Health, Hamadan University of Medical Sciences, Iran \\ A - research concept and design; $\mathrm{B}$ - collection and/or assembly of data; $\mathrm{C}$ - data analysis and interpretation; \\ $D$ - writing the article; $E$ - critical revision of the article; $F$ - final approval of the article
}

Address for correspondence

Masoud Abolvardi

E-mail: abolvardim@gmail.com

Funding sources

Hamadan University of Medical Sciences, Iran

(grant No. 950304950).

Conflict of interest

None declared

Received on May 19, 2018

Reviewed on June 9, 2018

Accepted on June 26, 2018

D0I

$10.17219 / \mathrm{dmp} / 92634$

Copyright

○ 2018 by Wroclaw Medical University

and Polish Dental Society

This is an article distributed under the terms of the

Creative Commons Attribution Non-Commercial License

(http://creativecommons.org/licenses/by-nc-nd/4.0/)

\begin{abstract}
Background. The width of the buccal corridor (BC) is one of the factors affecting smile attractiveness.

Objectives. The aim of this study was to determine the effects of the $B C$ size on the smile attractiveness of individuals with short, normal and long faces from the viewpoint of laypersons, general dentists and orthodontists.
\end{abstract}

Material and methods. Smiling photographs of male and female subjects who met the inclusion criteria were digitally altered to create 3 BC sizes (narrow: 2\%; normal: 15\%; wide: 28\%) and 3 facial types defined by the facial index (FI) (short face: $\mathrm{Fl} \leq 83.9$; normal face: $84.0 \leq \mathrm{Fl} \leq 87.9$; long face: $\mathrm{Fl} \geq 88.0$ ). Nine different combinations were made and the evaluators rated the overall attractiveness and acceptability of each smile on a 10-millimeter visual analog scale (VAS).

Results. A total of 53 raters (22 laypersons, 16 general dentists and 15 orthodontists) participated in this study. The orthodontists and general dentists had similar viewpoints and they preferred narrow and normal BCs over the wide ones in all facial types. Laypersons preferred normal BC for normal faces, while they did not distinguish different $B C s$ in short faces.

Conclusions. Variations in the BC size affect smile attractiveness in different facial types and wide BCs are attributed to the least attractive smiles. Due to the different viewpoints of laypersons and professionals in this regard, there is no justification for expanding the maxillary arch to achieve more attractive smiles.

Key words: buccal corridor, smile attractiveness, facial type

Słowa kluczowe: korytarz policzkowy, atrakcyjność uśmiechu, kształt twarzy 


\section{Introduction}

The increasing impact of facial attractiveness on selfperception and the way we are viewed by society cannot be overlooked. ${ }^{1-3}$ There are many different factors that constitute facial attractiveness. ${ }^{4-6}$ Among them, smile attractiveness is one of the most important. It affects our acceptability in social relationships by increasing selfconfidence and results in communicating with a more confident feeling. ${ }^{7-9}$

In an attractive smile, a series of factors, including consonant curvature of the upper dental arch with the lower lip, proper alignment of the teeth with no crowding and no spacing, the width of buccal corridors (BCs), the amount of dental and gingival display, the color of the teeth and gingiva, absence of cant in the occlusal plane, and the number of teeth displayed during the smile are involved. ${ }^{10-14}$ On the other hand, the facial type (long face, short face or normal face) is another fundamental factor involved in determining smile attractiveness. ${ }^{15}$

Among the abovementioned factors, the $\mathrm{BC}$ width is the most challenging factor in smile attractiveness, as there is no consensus in the literature about its ideal size. ${ }^{9,16,17}$ This can be related to different etiologic factors affecting the size of $\mathrm{BC}$, like maxillary deficiency in either transverse or sagittal dimensions, ${ }^{9,18-22}$ and extractions in the upper arch as a result of previous tooth loss or the orthodontic treatment plan. ${ }^{23}$ Most of the studies investigating the impact of $\mathrm{BC}$ on smile attractiveness used only close-up images of smiles. ${ }^{24-26}$ However, studies evaluating smile attractiveness should consider the facial type of the patient. The width of BCs in different facial types may seem different. ${ }^{17}$ At the same time, the perception of smile beauty and attractiveness may vary among different persons and among different societies. Smile attractiveness perception of a layperson may differ from that of professionals. ${ }^{27,28}$ Many articles have examined the effects of $\mathrm{BC}$ and the facial type on smile attractiveness, ${ }^{29-34}$ but no one has simultaneously evaluated the effect of these 2 factors from the viewpoints of laypersons, general dentists and orthodontists.

The present study is designed to assess smile attractiveness with regard to a different width of $\mathrm{BC}$ in different facial types from the viewpoint of general dentists, orthodontists and orthodontic patients as laypersons.

\section{Material and methods}

\section{Ethical approval and consent}

Ethical approval for this cross-sectional study was obtained from the Hamadan University of Medical Sciences Ethics Committee (Code: IR.UMSHA.REC.1395.36) and informed written consent was obtained from each patient whose photograph was used.

\section{Image series construction}

The frontal posed smile view of 2 subjects ( 1 male and 1 female) who met the inclusion criteria was chosen for this study. The inclusion criteria were as follows:

- complete incisors shown at smile (100\%);

- coordination between the upper dental arch and the curvature of the lower lip during the smile (consonant smile arch);

- ideal anterior tooth alignment with no crowding and no spacing;

- medium BC size (15\% of the distance between the right and left commissures $)^{17,35,36}$;

- normal (mesoprosopic) facial type (facial index $(\mathrm{FI})=84.0-87.9 \%){ }^{34}$

The facial type of the subjects was determined using FI, which is the result of the division of the anterior face height $(\mathrm{mm})$ by the bizygomatic width $(\mathrm{mm})$. Anterior face height is the distance between the nasion soft tissue $(\mathrm{Na})$ and the menton soft tissue (Men). The bizygomatic width of the face is the distance between the most prominent points on the zygomatic arches.

$$
\mathrm{FI}=[(\mathrm{Na}-\mathrm{Men}) / \text { bizygomatic width }] \times 100,
$$

where:

FI - facial index;

$\mathrm{Na}$ - nasion soft tissue;

Men - menton soft tissue.

After filling out the informed consent form, each patient's frontal posed smile photograph was changed using Adobe Photoshop (CS5; Adobe Systems, San Jose, USA) to produce 2 types of independent variables:

- 3 different facial types according to the following standards: euryprosopic (short face): FI $\leq 83.9$; mesoprosopic (normal face): $84.0 \leq \mathrm{FI} \leq 87.9$; and leptoprosopic (long face): FI $\geq 88.0$;

- 3 different types of the BC size: narrow: $2 \%$ of the distance between the right and left lip commissures; normal: $15 \%$ of the distance between the right and left lip commissures; and wide: $28 \%$ of the distance between the right and left lip commissures.

Combining the 2 variables, 9 different posed smile photographs of each subject were obtained (Fig. 1,2). Then, the photographs were numbered in a randomized order, determined by the website www.randomizer.org, and these randomized sequences were given to each rater.

\section{Raters}

Three groups of raters were involved in this study:

- laypersons - orthodontic patients who had not started their orthodontic treatment yet (to avoid any impact of the expertise of orthodontists on their point of view); 

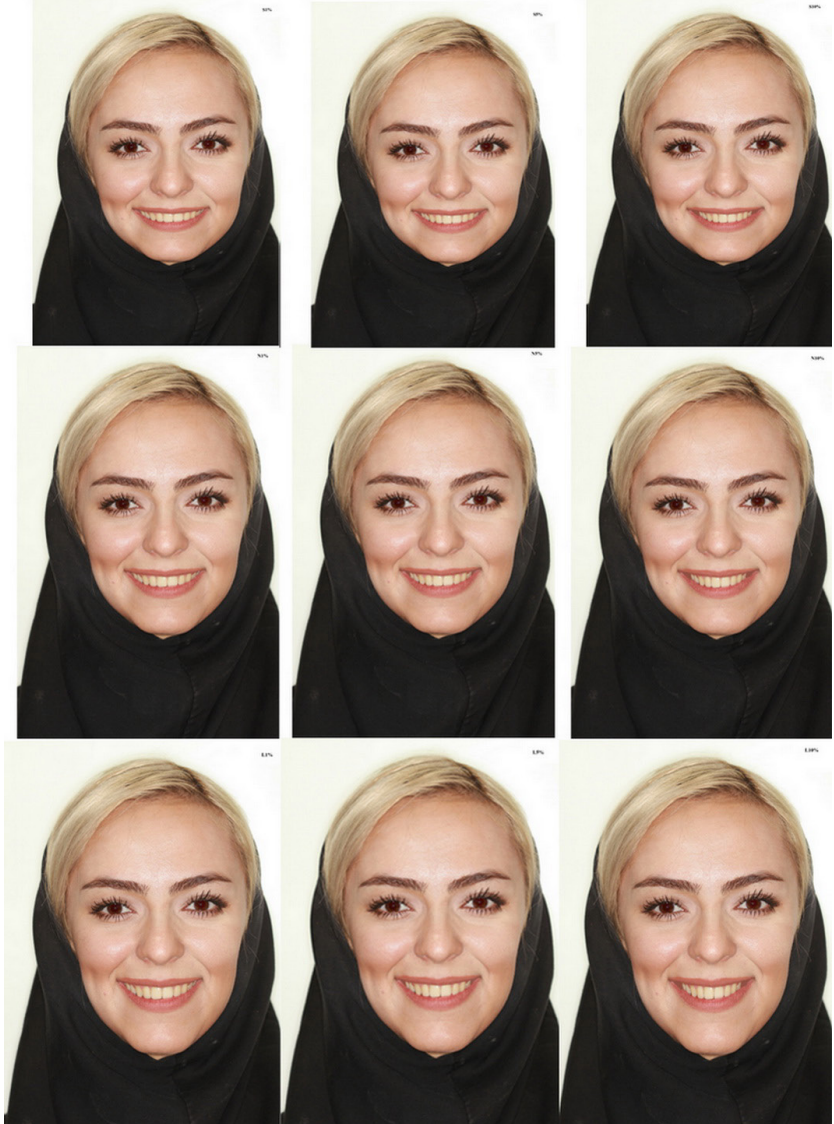

Fig. 1. Female subject sequence of smiles (different BC sizes and different facial types)

BC - buccal corridor.

- general dentists - general dentists who had not participated in orthodontic courses;

- orthodontists - orthodontists with clinical experience of at least 1 year.

The generated randomized sequences were shown to each evaluator; they were asked to rate the smile attractiveness of each picture by selecting a point along a visual analog scale (VAS), $10 \mathrm{~cm}(100 \mathrm{~mm})$ in length. The VAS consisted of a bar labeled "Zero: the least attractive smile" on the left and "Ten: the most attractive one" on the right. The rate of smile attractiveness was reported as a value from 0 to 10 . Smile attractiveness evaluations were done twice, with an interval of 4 weeks. In order to determine the reliability of the evaluations, 18 raters were selected randomly in such a way that each rater group included 6 samples.

\section{Statistical analysis}

Establishing a statistical power of $95 \%$ and $\alpha$ level of 0.05 , the calculated sample size for each group of raters was 14 individuals. The data was analyzed by SPSS v. 17.0 software (IBM Corp., Armonk, USA). The repeated measures analysis of variance (ANOVA) was utilized for comparing differences between the groups. The least significant differ-

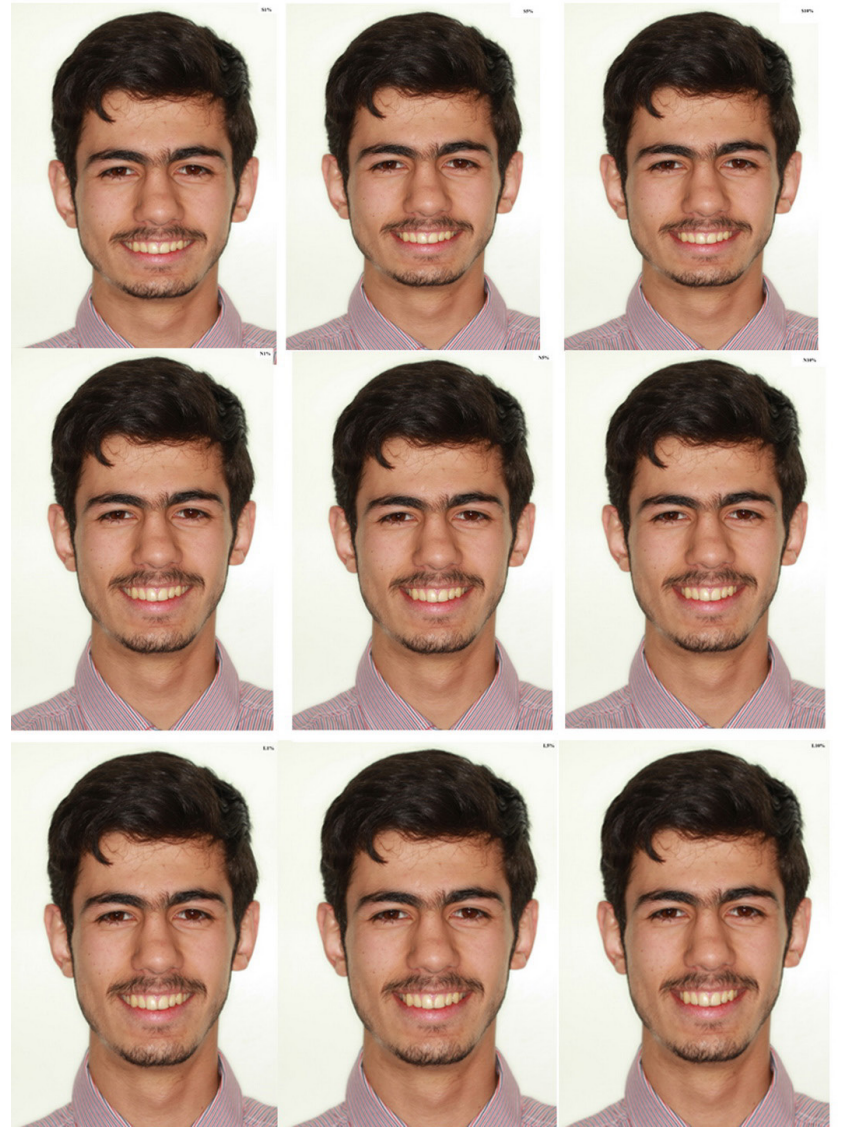

Fig. 2. Male subject sequence of smiles (different BC sizes and different facial types)

$\mathrm{BC}$ - buccal corridor.

ence (LSD) test was used for all pairwise comparisons. The intraclass correlation coefficient (ICC) was used to find the correlation between the $1^{\text {st }}$ and the $2^{\text {nd }}$ VAS score.

\section{Results}

A total of 53 raters - 29 males (54.7\%) and 24 females (45.3\%) - participated in this study (22 laypersons, 16 general dentists and 15 orthodontists). The average age of the raters was $25.63 \pm 7.87$ years for laypersons, $29.93 \pm 5.84$ years for general dentists and $34.73 \pm 7.54$ years for orthodontists (Table 1). The average period of clinical experience was $5.56 \pm 1.39$ years and $5.86 \pm 1.39$ years for general dentists and orthodontists, respectively.

Table 1. Descriptive characteristics of the raters

\begin{tabular}{|l|c|c|c|}
\multicolumn{1}{|c|}{ Raters } & Number (\%) & $\begin{array}{c}\text { Age [years] } \\
\text { mean } \pm \text { SD }\end{array}$ & $\begin{array}{c}\text { Clinical experience } \\
\text { [years] mean } \pm \text { SD }\end{array}$ \\
\hline Laypersons & $22(41.5)$ & $25.63 \pm 7.87$ & - \\
General dentists & $16(30.2)$ & $29.93 \pm 5.84$ & $5.56 \pm 1.39$ \\
Orthodontists & $15(28.3)$ & $34.73 \pm 7.54$ & $5.86 \pm 1.39$ \\
Total & $53(100)$ & $29.50 \pm 8.03$ & - \\
\hline
\end{tabular}

SD - standard deviation. 
Table 2. Smile attractiveness scores (VAS score), expressed as mean \pm standard deviation (SD), among different groups of BCs in different facial types compared using repeated measures analysis of variance (ANOVA)

\begin{tabular}{|c|c|c|c|c|c|}
\hline Facial type & Raters & Narrow BC & Normal BC & Wide BC & $\mathrm{p}$-value \\
\hline \multirow{3}{*}{ Short face } & layperson & $4.91 \pm 0.41$ & $4.45 \pm 0.32$ & $4.73 \pm 0.38$ & 0.496 \\
\hline & general dentist & $5.25 \pm 0.41$ & $5.06 \pm 0.36$ & $3.72 \pm 0.38$ & 0.002 \\
\hline & orthodontist & $4.93 \pm 0.41$ & $4.07 \pm 0.30$ & $3.50 \pm 0.44$ & $<0.001$ \\
\hline \multirow{3}{*}{ Normal face } & layperson & $6.14 \pm 0.37$ & $6.80 \pm 0.31$ & $5.34 \pm 0.30$ & 0.003 \\
\hline & general dentist & $7.44 \pm 0.39$ & $6.94 \pm 0.32$ & $4.87 \pm 0.39$ & $<0.001$ \\
\hline & orthodontist & $7.73 \pm 0.38$ & $7.13 \pm 0.36$ & $4.97 \pm 0.41$ & $<0.001$ \\
\hline \multirow{3}{*}{ Long face } & layperson & $5.50 \pm 0.34$ & $5.45 \pm 0.32$ & $4.32 \pm 0.34$ & $<0.001$ \\
\hline & general dentist & $6.50 \pm 0.37$ & $6.12 \pm 0.37$ & $3.94 \pm 0.44$ & $<0.001$ \\
\hline & orthodontist & $6.57 \pm 0.40$ & $5.47 \pm 0.35$ & $4.17 \pm 0.35$ & $<0.001$ \\
\hline \multirow{3}{*}{$\begin{array}{l}\text { Regardless } \\
\text { of facial type }\end{array}$} & layperson & $5.51 \pm 0.22$ & $5.57 \pm 0.20$ & $4.79 \pm 0.20$ & $<0.001$ \\
\hline & general dentist & $6.40 \pm 0.24$ & $6.04 \pm 0.21$ & $4.18 \pm 0.24$ & $<0.001$ \\
\hline & orthodontist & $6.41 \pm 0.26$ & $5.56 \pm 0.23$ & $4.21 \pm 0.24$ & $<0.001$ \\
\hline
\end{tabular}

VAS - visual analog scale; BC - buccal corridor.

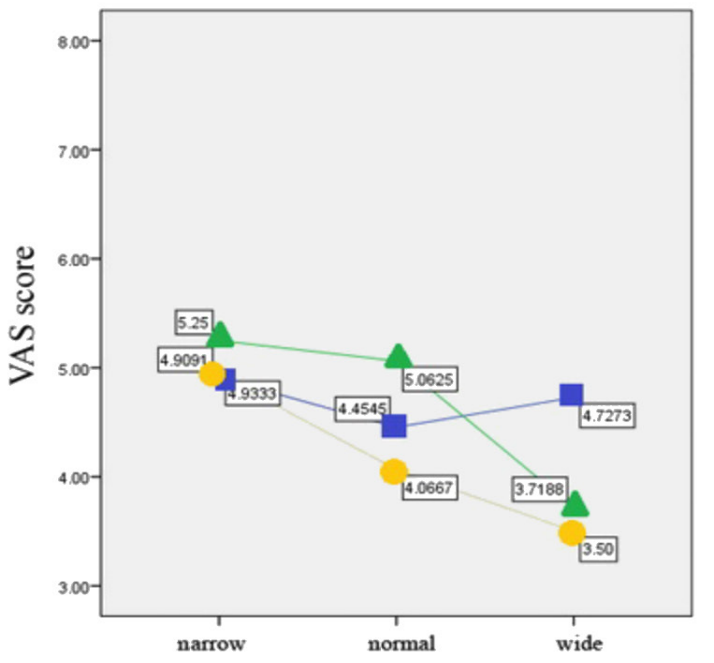

A short facial type

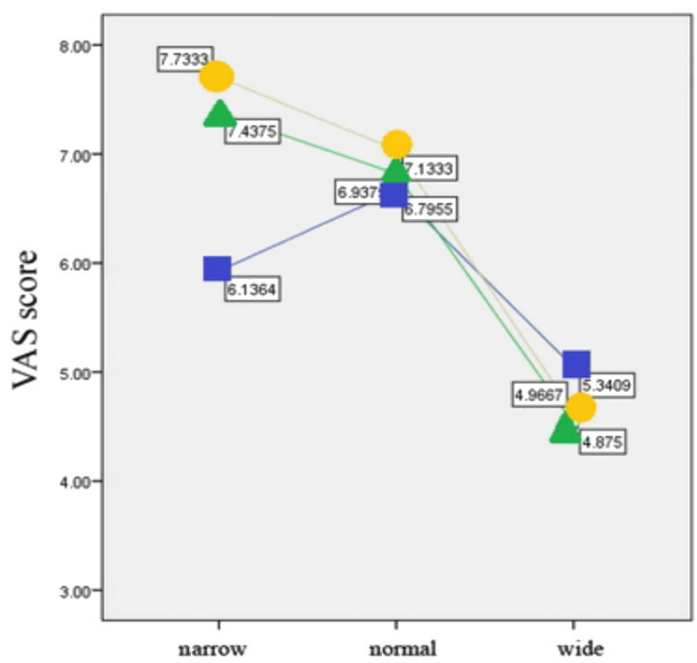

B normal facial type
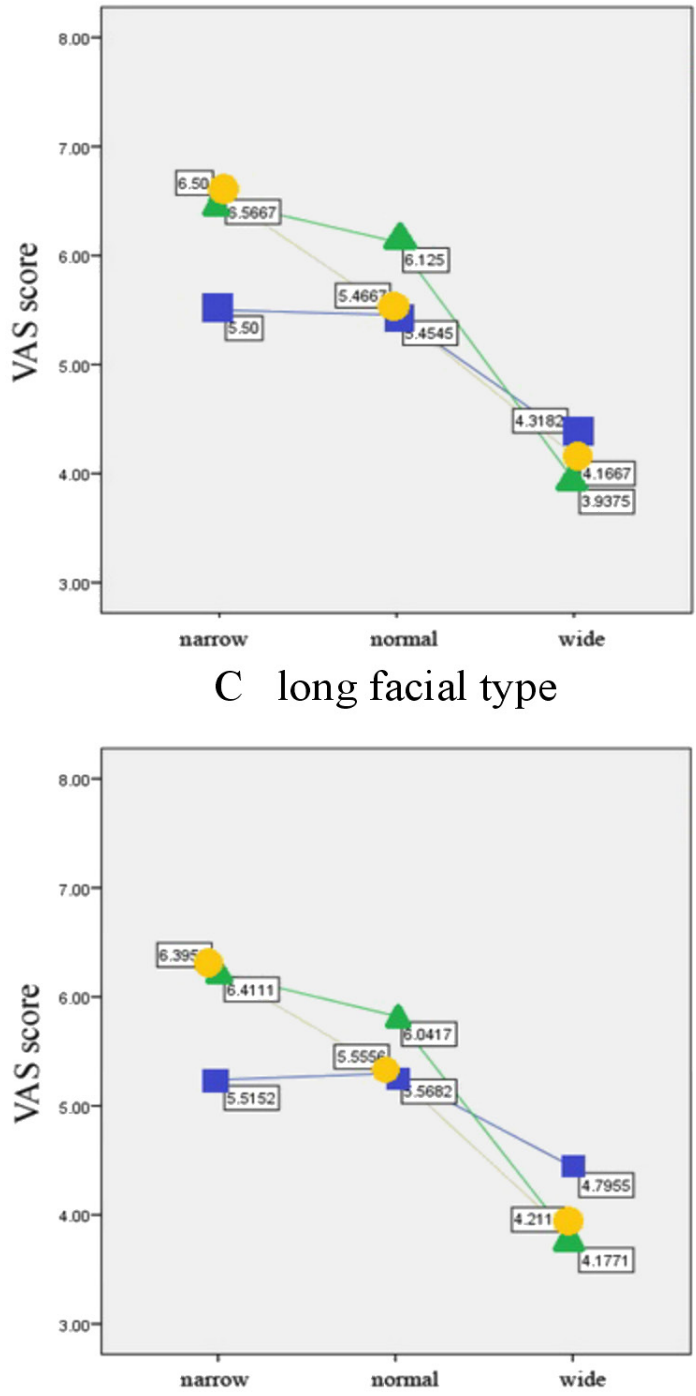

D regardless of facial type

Fig. 3. Smile attractiveness scores (VAS score) among different groups of BCs in different facial types VAS - visual analog scale; BC - buccal corridor. 
Table 3. Pairwise comparisons using the LSD test of smile attractiveness scores (VAS score), expressed as mean \pm standard deviation (SD), among different groups of BCs in different facial types

\begin{tabular}{|c|c|c|c|c|}
\hline Facial type & Raters & \multicolumn{2}{|c|}{ BC type } & $p$-value \\
\hline \multirow{9}{*}{ Short face } & \multirow{3}{*}{ layperson } & narrow & normal & 0.222 \\
\hline & & narrow & wide & 0.656 \\
\hline & & normal & wide & 0.478 \\
\hline & \multirow{3}{*}{ general dentist } & narrow & normal & 0.698 \\
\hline & & narrow & wide & 0.001 \\
\hline & & normal & wide & 0.005 \\
\hline & \multirow{3}{*}{ orthodontist } & narrow & normal & 0.001 \\
\hline & & narrow & wide & $<0.001$ \\
\hline & & normal & wide & 0.081 \\
\hline \multirow{9}{*}{ Normal face } & \multirow{3}{*}{ layperson } & narrow & normal & 0.144 \\
\hline & & narrow & wide & 0.066 \\
\hline & & normal & wide & $<0.001$ \\
\hline & \multirow{3}{*}{ general dentist } & narrow & normal & 0.161 \\
\hline & & narrow & wide & $<0.001$ \\
\hline & & normal & wide & $<0.001$ \\
\hline & \multirow{3}{*}{ orthodontist } & narrow & normal & 0.062 \\
\hline & & narrow & wide & $<0.001$ \\
\hline & & normal & wide & $<0.001$ \\
\hline \multirow{9}{*}{ Long face } & \multirow{3}{*}{ layperson } & narrow & normal & 0.870 \\
\hline & & narrow & wide & $<0.001$ \\
\hline & & normal & wide & $<0.001$ \\
\hline & \multirow{3}{*}{ general dentist } & narrow & normal & 0.419 \\
\hline & & narrow & wide & $<0.001$ \\
\hline & & normal & wide & $<0.001$ \\
\hline & \multirow{3}{*}{ orthodontist } & narrow & normal & 0.004 \\
\hline & & narrow & wide & $<0.001$ \\
\hline & & normal & wide & 0.001 \\
\hline \multirow{9}{*}{ Regardless of facial type } & \multirow{3}{*}{ layperson } & narrow & normal & 0.805 \\
\hline & & narrow & wide & 0.001 \\
\hline & & normal & wide & $<0.001$ \\
\hline & \multirow{3}{*}{ general dentist } & narrow & normal & 0.155 \\
\hline & & narrow & wide & $<0.001$ \\
\hline & & normal & wide & $<0.001$ \\
\hline & \multirow{3}{*}{ orthodontist } & narrow & normal & $<0.001$ \\
\hline & & narrow & wide & $<0.001$ \\
\hline & & normal & wide & $<0.001$ \\
\hline
\end{tabular}

LSD test - the least significant difference test; VAS - visual analog scale; BC - buccal corridor.

All 53 raters returned their completed papers. A good agreement between the $1^{\text {st }}$ and the $2^{\text {nd }}$ evaluation of smile attractiveness was observed (ICC $=0.884-0.952$ ).

In the short facial type, repeated measurements ANOVA showed a significant difference among smile attractiveness of different BC groups rated by orthodontists $(\mathrm{p}<0.001)$ and general dentists $(\mathrm{p}=0.002)$ (Table 2). General dentists' high score was $5.25 \pm 0.41$ for the narrow BC type. They preferred narrow and normal $B C$ types over the wide type ( $p=0.001$ and $p=0.005$, respectively), but there was no difference between the narrow and normal ones
( $\mathrm{p}=0.698$ ). Orthodontists' high score was $4.93 \pm 0.41$ for the narrow BC type. They preferred narrow over normal and wide $B C$ types ( $\mathrm{p}=0.001$ and $\mathrm{p}<0.001$, respectively), but there was no difference between the normal and wide types $(\mathrm{p}=0.081)$. While laypersons' scores showed no significant difference among different $\mathrm{BC}$ groups $(\mathrm{p}=0.496)$, the narrow type reached the highest score $(4.91 \pm 0.41)$ (Table 3, Fig. 3).

In the normal facial type, a significant difference in smile attractiveness was seen among different $\mathrm{BC}$ groups rated by laypersons $(p=0.003)$, general dentists $(p<0.001)$ and 
orthodontists $(\mathrm{p}<0.001)$ (Table 2). Laypersons' high score was $6.80 \pm 0.31$ for the normal $\mathrm{BC}$ type. They preferred the normal over the wide type $(\mathrm{p}<0.001)$, but there was no difference between the narrow and normal types $(\mathrm{p}=0.144)$ and between the narrow and wide ones $(p=0.066)$. General dentists, with a high score of $7.44 \pm 0.39$ for the narrow $\mathrm{BC}$ type, preferred the narrow and normal over the wide type ( $\mathrm{p}<0.001$ for both), but there was no difference between the narrow and normal ones $(\mathrm{p}=0.161)$. Orthodontists' high score $(7.73 \pm 0.38)$ was assigned to the narrow $B C$ type. They preferred the narrow and normal over the wide type ( $\mathrm{p}<0.001$ for both), but there was no difference between the narrow and normal types $(\mathrm{p}=0.062)$ (Table 3, Fig. 3).

With respect to the long facial type, a significant difference in smile attractiveness was seen among different $\mathrm{BC}$ groups rated by laypersons $(\mathrm{p}<0.001)$, general dentists $(\mathrm{p}<0.001)$ and orthodontists $(\mathrm{p}<0.001)$ (Table 2). Laypersons, with a high score of $5.50 \pm 0.34$ for the narrow $\mathrm{BC}$ type, preferred the narrow and normal over the wide $B C$ type $(p<0.001$ for both), but there was no difference between the narrow and normal types $(p=0.870)$. General dentists' high score was $6.50 \pm 0.37$ for the narrow $\mathrm{BC}$ type. They also preferred the narrow and normal types over the wide $\mathrm{BC}$ type ( $\mathrm{p}<0.001$ for both), but there was no difference between the narrow and normal ones ( $\mathrm{p}=0.419)$. Orthodontists' high scores $(6.57 \pm 0.40$ and $5.47 \pm 0.35$ ) were assigned to the narrow and normal BC types, respectively. They preferred the narrow over the normal $(\mathrm{p}=0.004)$ and wide types $(\mathrm{p}<0.001)$. They also preferred the normal over the wide $\mathrm{BC}$ type $(\mathrm{p}=0.001)$ (Table 3, Fig. 3).

Overall, regardless of facial types, a significant difference in smile attractiveness was seen among the different $\mathrm{BC}$ groups rated by laypersons $(\mathrm{p}<0.001)$, general dentists $(\mathrm{p}<0.001)$ and orthodontists $(\mathrm{p}<0.001)$ (Table 2). Laypersons gave a high score of $5.57 \pm 0.20$ to the normal $\mathrm{BC}$ type. They preferred the narrow and normal types over the wide one ( $\mathrm{p}=0.001$ and $\mathrm{p}<0.001$, respectively), but there was no difference between the narrow and normal types $(\mathrm{p}=0.805)$. General dentists' high score was $6.40 \pm 0.24$ and it was assigned to the narrow BC type. They preferred the narrow and normal over the wide $B C$ type ( $\mathrm{p}<0.001$ for both), but there was no difference between the narrow and normal ones $(\mathrm{p}=0.155)$. Orthodontists' high score was $6.41 \pm 0.26$ for the narrow BC type. They preferred the narrow over the normal and wide types, and also the normal over the wide BCs ( $\mathrm{p}<0.001$ for all) (Table 3, Fig. 3).

\section{Discussion}

The present study investigated the impact of the $\mathrm{BC}$ size among different facial types on the attractiveness of the smile. Previous studies showed both of these factors were important in this regard. ${ }^{9,16,17}$ Furthermore, in the literature, different judgments of smile attractiveness by different raters have been shown. ${ }^{27,28,30,37}$ Some studies assessed in this regard 5 different sizes of BC $(2 \%, 10 \%, 15 \%, 22 \%$, and $28 \%)^{17,35,36}$ and some others used 6 sizes $(0 \%, 5 \%, 10 \%$, $15 \%, 20 \%$, and $25 \%) .30,37$ In our study, we constructed only 3 sizes of BC ( $2 \%, 15 \%$ and $28 \%)$. These were matched to the narrow, medium and wide sizes of the other studies and they seemed to be simpler to differentiate, especially for laypersons. Furthermore, regarding the facial type, some of the studies assessed just 2 facial types (short face and long face $)^{17}$ and some assessed 3 facial types. ${ }^{36} \mathrm{We}$ constructed 3 facial types (short face, normal face and long face) according to FI in order to compare smile attractiveness in each facial type.

Finally, regarding raters, most of the studies compared 2 types of raters, usually orthodontists and laypersons. ${ }^{17,30,37}$ In our study, we used 3 groups of raters: orthodontists, general dentists and laypersons. This design could cover different judgments between laypersons and professionals, and also differences between the viewpoints of general dentists and orthodontists, who are both highly involved in dental treatment plans and consultations.

Our results showed a total agreement from the viewpoints of general dentists and orthodontists. Although it was not always statistically significant, these raters preferred narrow over normal, and normal over wide BC types in all facial types. On the other hand, laypersons preferred normal and narrow types over the wide one, with the highest score for the normal $\mathrm{BC}$ type. This difference between raters' viewpoints could be fundamental for practitioners when deciding upon expansion/extraction treatments plans, especially in borderline cases. The results showed that, although it was not statistically significant, the normal $\mathrm{BC}$ size was more attractive than narrow one from the point of view of laypersons. On the other hand, professionals preferred expanded arches with narrow $\mathrm{BCs}$ over the normal ones. Furthermore, both laypersons and professionals believed that wide BCs were attributed to the least attractive smiles, and this was consistent with the results of previous studies. ${ }^{17,30,37}$ Therefore, it could be concluded that in normal BC size patients with any facial type, it is better to maintain or expand the upper arch. Treatment plans which increase the width of the $\mathrm{BC}$ are not preferable from the viewpoints of any of the raters.

As discussed above, wide BCs resulted in the least attractive smiles in all facial types and among all raters, with the exception of the short facial type in the opinion of laypersons. When laypersons judged smile attractiveness in the short facial type, the wide BC type had a score of $4.73 \pm 0.38$, which was between the normal and narrow BCs scores (4.45 \pm 0.32 and $4.91 \pm 0.41$, respectively). Statistical analysis showed that there was no significant difference between each of these scores. This unusual pattern could be related to such factors as total lower scores 
of short facial types than other facial types or the small sample size of raters. On the other hand, when all facial types are combined together, a predictable pattern is observed in the laypersons' opinions. They also marked the wide $\mathrm{BC}$ type as the least attractive one.

In the present study, all raters could distinguish the impact of different BCs on smile attractiveness in normal and long facial types, but laypersons could not differentiate between different BCs in short faces (Table 2). These findings are consistent with the results obtained by Zange et al. as to the long facial type part; orthodontists in both studies preferred the narrow BC for long face patients and they could differentiate between each pair of BC sizes. ${ }^{17}$ Laypersons were unable to differentiate the attractiveness of smiles except for the wide $\mathrm{BC}$ type. Conversely, in regard to the short facial type, our study is in contrast to the study by Zange et al. ${ }^{17}$ While we observed that laypersons could not find the differences between each $\mathrm{BC}$, Zange et al. reported that laypersons differentiated each of the BC sizes included in our study (2\%, $15 \%$ and 28\%). Comparing the methodology, they constructed a video of photographs in which raters had only $15 \mathrm{~s}$ to evaluate each image and could not go back to see the previous image. They also were not able to compare the images at the same time. In our study, we showed all 9 images of both patients at the same time, with no restriction on the time of evaluation.

Our study investigated the impact of the BC size among different facial types from different viewpoints. It is suggested for future investigators to consider the effect of the patients' sex and also to analyze the viewpoints of different raters, regarding not only their profession, but also their gender, in order to clarify whether the sex of the patients and/or of the raters has any effect on the results.

\section{Conclusions}

For all facial types, orthodontists and general dentists similarly stated that the narrower the BCs are, the more attractive the smile is. Wide (28\%) BCs were attributed to the least attractive smiles in all facial types. In normal faces, laypersons, in contrast to the professionals, preferred the normal (15\%) BC size. They also could not differentiate the effects of different BCs on the smile attractiveness of the short facial type.

\section{References}

1. Brown A, Knight T. Shifts in media images of women appearance and social status from 1960 to 2010: A content analysis of beauty advertisements in two Australian magazines. J Aging Stud. 2015;35:74-83.

2. Jack RE, Schyns PG. The human face as a dynamic tool for social communication. Curr Biol. 2015;25(14):R621-634.

3. Dion K, Berscheid E, Walster E. What is beautiful is good. J Pers Soc Psychol. 1972;24(3):285-290.

4. Faure J, Bolender Y. Beauty judgment: Review of the literature [in French]. Orthod Fr. 2014;85(1):3-29.
5. Heppt WJ, Vent J. The facial profile in the context of facial aesthetics. Facial Plast Surg. 2015;31(5):421-430.

6. Tole N, Lajnert V, Kovacevic Pavicic D, Spalj S. Gender, age, and psychosocial context of the perception of facial esthetics. J Esthet Restor Dent. 2014;26(2):119-130.

7. Van der Geld P, Oosterveld P, Van Heck G, Kuijpers-Jagtman AM. Smile attractiveness. Self-perception and influence on personality. Angle Orthod. 2007;77(5):759-765.

8. LaFrance M, Hecht MA, Paluck EL. The contingent smile: A meta-analysis of sex differences in smiling. Psychol Bull. 2003;129(2):305-334.

9. Ackerman JL, Ackerman MB, Brensinger CM, Landis JR. A morphometric analysis of the posed smile. Clin Orthod Res. 1998;1(1):2-11.

10. Ahrari F, Heravi F, Rashed R, Zarrabi MJ, Setayesh Y. Which factors affect dental esthetics and smile attractiveness in orthodontically treated patients? J Dent (Tehran). 2015;12(7):491-503.

11. Kaya B, Uyar R. The impact of occlusal plane cant along with gingival display on smile attractiveness. Orthod Craniofac Res. 2016;19(2):93-101.

12. Machado AW, McComb RW, Moon W, Gandini LG. Influence of the vertical position of maxillary central incisors on the perception of smile esthetics among orthodontists and laypersons. J Esthet Restor Dent. 2013;25(6):392-401.

13. Sarver DM. The importance of incisor positioning in the esthetic smile: The smile arc. Am J Orthod Dentofacial Orthop. 2001;120(2):98-111.

14. Jenny J. A social perspective on need and demand for orthodontic treatment. Int Dent J. 1975;25(4):248-256.

15. Johnston DJ, Hunt O, Johnston CD, Burden DJ, Stevenson M, Hepper $P$. The influence of lower face vertical proportion on facial attractiveness. Eur J Orthod. 2005;27(4):349-354.

16. Proffit WR, Fields HW, Sarver DM. Contemporary Orthodontics. $4^{\text {th }}$ ed. St. Louis, MO: Mosby; 2007:187,188.

17. Zange SE, Ramos AL, Cuoghi OA, de Mendonça MR, Suguino R. Perceptions of laypersons and orthodontists regarding the buccal corridor in long- and short-face individuals. Angle Orthod. 2011;81(1):86-90.

18. Sarver DM, Ackerman MB. Dynamic smile visualization and quantification: Part 1. Evolution of the concept and dynamic records for smile capture. Am J Orthod Dentofacial Orthop. 2003;124(1):4-12.

19. Sarver DM, Ackerman MB. Dynamic smile visualization and quantification: Part 2. Smile analysis and treatment strategies. Am J Orthod Dentofacial Orthop. 2003;124(2):116-127.

20. McNamara JA. Maxillary transverse deficiency. Am J Orthod Dentofacial Orthop. 2000;117(5):567-570.

21. Ackerman JL, Proffit WR, Sarver DM. The emerging soft tissue paradigm in orthodontic diagnosis and treatment planning. Clin Orthod Res. 1999;2(2):49-52.

22. Ackerman MB. Buccal smile corridors. Am J Orthod Dentofacial Orthop. 2005;127(5):528-529.

23. Ghafari JG. Emerging paradigms in orthodontics - an essay. Am J Orthod Dentofacial Orthop. 1997;111(5):573-580.

24. Rittera DE, Gandini L, Pinto Ados S, Locks A. Esthetic influence of negative space in the buccal corridor during smiling. Angle Orthod. 2006;76(2):198-203.

25. Parekh S, Fields HW, Beck FM, Rosenstiel SF. The acceptability of variations in smile arc and buccal corridor space. Orthod Craniofac Res. 2007;10(1):15-21.

26. Maulik C, Nanda R. Dynamic smile analysis in young adults. Am J Orthod Dentofacial Orthop. 2007;132(3):307-315.

27. Jørnung J, Fardal $\varnothing$. Perceptions of patients' smiles: A comparison of patients' and dentists' opinions. J Am Dent Assoc. 2007;138(12):1544-1553;quiz 613,614.

28. Springer NC, Chang C, Fields HW, et al. Smile esthetics from the layperson's perspective. Am J Orthod Dentofacial Orthop. 2011;139(1):e91-e101.

29. Meyer AH, Woods MG, Manton DJ. Maxillary arch width and buccal corridor changes with orthodontic treatment. Part 2: Attractiveness of the frontal facial smile in extraction and nonextraction outcomes. Am J Orthod Dentofacial Orthop. 2014;145(3):296-304.

30. Ioi $\mathrm{H}$, Kang $\mathrm{S}$, Shimomura $\mathrm{T}$, et al. Effects of buccal corridors on smile esthetics in Japanese and Korean orthodontists and orthodontic patients. Am J Orthod Dentofacial Orthop. 2012;142(4):459-465. 
31. Janson G, Branco NC, Fernandes TM, Sathler R, Garib D, Lauris JR. Influence of orthodontic treatment, midline position, buccal corridor and smile arc on smile attractiveness. Angle Orthod. 2011;81(1):153-161.

32. Grover N, Kapoor DN, Verma S, Bharadwaj P. Smile analysis in different facial patterns and its correlation with underlying hard tissues. Prog Orthod. 2015;16:28.

33. Chou JC, Thompson GA, Aggarwal HA, Bosio JA, Irelan JP. Effect of occlusal vertical dimension on lip positions at smile. J Prosthet Dent. 2014;112(3):533-539.

34. Williams RP, Rinchuse DJ, Zullo TG. Perceptions of midline deviations among different facial types. Am J Orthod Dentofacial Orthop. 2014;145(2):249-255.

35. Oshagh M, Zarif NH, Bahramnia F. Evaluation of the effect of buccal corridor size on smile attractiveness. Eur J Esthet Dent. 2010;5(4):370-380.

36. Pithon MM, Rocha KS, Costa BdN, et al. Perceptions of brachyfacial, mesofacial and dolichofacial individuals with regard to the buccal corridor in different facial types. J Appl Oral Sci. 2014;22(3):382-389.

37. Ioi H, Nakata S, Counts AL. Effects of buccal corridors on smile esthetics in Japanese. Angle Orthod. 2009;79(4):628-633. 